\title{
Community Participation in Household Waste Management: An Exploratory Study in Indonesia
}

\author{
Anantya Novega Santoso ${ }^{1}$, and Farizal ${ }^{1, *}$ \\ ${ }^{1}$ Department of Industrial Engineering, University of Indonesia, Depok 16424, Indonesia
}

\begin{abstract}
The increased population and economic of the community indirectly affect the amount of household waste produced by the community. Unfortunately, this is not accompanied by good waste management from the community level. Management of household waste at the community level can be done by sorting waste. The habit of people to dispose of garbage without sorting can be a problem in implementing 3R activities (Recycling, Reducing, and Reusing). The purpose of this study is to find out what factors influence the community in sorting household waste. This research is based on the Theory of Planned Behavior (TPB) which considers several factors such as attitudes, subjective norms, and behavioral controls to influence someone to make intentions in behavior and expand the TPB conceptual model to overcome gaps. The results of this study came from a survey with 301 respondents in two locations namely DKI Jakarta and Depok. The results of this study indicate that attitudinal factors have the most significant influence on the intention and behavior of sorting garbage. While other factors such as demographics, subjective norms and perceptions of behavioral control do not have a significant effect.
\end{abstract}

Keywords: Municipal Solid Waste; Waste Separation; Theory of Planned Behavior.

\section{Introduction}

The increasing population, urbanization, sustainable economic growth, industrialization, and increasing public welfare have led to an increase in household waste production [1]. Increasing the amount of waste and direct disposal into the environment without recycling can threaten the environment and public health [2]. Recycling is considered as one of the most important strategies to reduce the adverse effects of waste on the environment and waste disposal. Recycling is a process in which existing materials are used previously sorted, collected, processed, remade and reused [3]. Recycling activities require the sorting of waste from the source, this is an important component of the waste management system [4]. The selection of waste from the source is referred to as the sorting of waste carried out at the household level. The waste produced by household activities is called household waste [5]. Household waste is one of the main sources of municipal solid waste producers which consumes most of the cost of municipal waste management [6].
Amount of Waste Produced in ASEAN

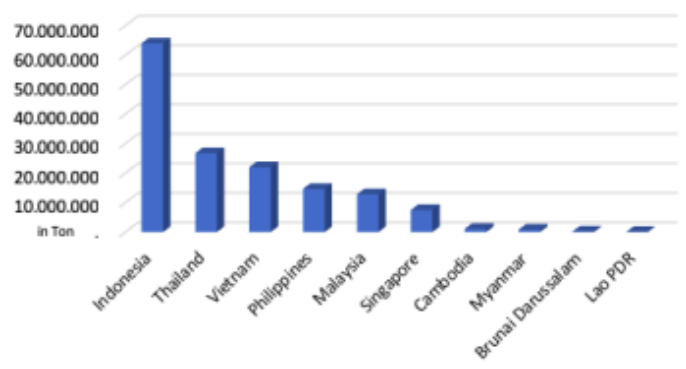

Fig 1. Amount of Waste Produced in ASEAN [7]

According to a report from the United Nations Environment in 2017 [7], Indonesia produces 64 million tons of waste per year (Fig.1). This is the same as the amount of garbage as much as $0.7 \mathrm{~kg}$ of waste per person per day. Still, according to the report, the characteristics of the household waste in Indonesia are dominated by organic waste with a presentation of $60 \%$ followed by plastic waste by $14 \%$. Whereas based on a report from the Central Bureau of Statistics (BPS) in 2014 the percentage of Indonesians who sorted their waste was only $18.84 \%$ and the remaining $81.16 \%$ were people who did not sort out their waste [8].The Ministry of Environment and Forestry (KLHK) stated in the 2017 environmental quality index report that the potential

\footnotetext{
* Corresponding author: farizal@eng.ui.ac.id
} 
hazards that affect the environment in each province are waste dumps [9].

The Indonesian government has several Act and Regulations on waste management at the national and regional levels. For example, Act 18/2008 regarding solid waste management, government regulation 81/2012 regarding household waste and Minister of Environment regulation 13/2012 regarding $3 R$ have been enacted [1012]. However, the problem is with the waste management system in the community. That is by way of household waste being dumped on the roadside, then the garbage truck collects it and directly transports it to the landfill site. Alternatively, the waste cart will collect the waste from the roadside waste bin on the roadside and move it to the designated transfer station. Then, the garbage truck collects waste from the transfer station and moves it to a landfill site. In this process, there is no $3 \mathrm{R}$ especially waste separation activities. The lack of basic infrastructure to implement sustainable solid waste management is also a severe obstacle [13].

This study aims to describe the intention of the household community to separate municipal waste at the household level. To describe this intention, a discussion of information gaps in the literature was carried out, identifying the main drivers of behavior, linking the direct and indirect relationships between factors that influence in terms of intention to sort waste at the household level. The TPB framework is used and expanded by identifying and prioritizing the main constructs that influence community intentions and behavior through semi-structured interviews followed by qualitative analysis and quantitative modeling after conducting literature studies.

\section{Literature Review}

Conceptual modeling is based on several basic theories that refer to behavior. The willingness of the community to sort waste can be formed from other intentions and variables.

\subsection{Waste Separation}

Various waste management strategies have been attempted in most cities and countries in the field of municipal solid waste (MSW) integrated management. The key to the success of such strategies has generally been found to be MSW source separation, which is considered an effective means of enhancing waste recycling and disposal reduction [14]. Waste separation refers to the separation of MSW into several categories at the generation source according to the different characteristics of each material before further treatment. The main body of source separation activity is the separation actor [15]. Waste separation is a behavior that requires considerable efforts on the part of the individual as household waste must be sorted, prepared and stored. Consequently, the separation decision is likely to be complex and several factors to be taken into consideration [16].

\subsection{Theory of Planned Behavior}

Theory of Planned Behavior (TPB) [17] explained by [18] through [16] is a theoretical framework to assist an understanding of perceived effectiveness and public attitudes towards the scheme under study. The use of psychological models in this theory is important to understand the reaction of households to food waste separation programs that require to support this choice. The theory, which was developed from the previous Theory of Reasoned Action (TRA), assumes that people behave rationally, and they consider the implications of their actions. TPB hypothesizes that the direct determinant of behavior is the intention of the individual to do, or not to behave. The intention, in turn, is influenced by two factors, namely attitude (evaluation of positive or negative individuals of behavioral behavior) and subjective norms (individual perceptions of social pressure to do or not conduct behavior). The TPB provides a theoretical framework for systematically identifying the factors which influence the separation decision. TPB also allowed individuals who have positive attitudes, and think that there is adequate normative support, and perceive that they can easily engage in the activity, should have strong intentions to perform the behavior [19].

\section{Research Method}

\subsection{Development of the framework}

According to TPB's theory [16], human behavior is guided by three types of considerations: beliefs about possible behavioral outcomes and evaluation of these results (attitudes), beliefs about other people's normative expectations and motivation to comply with these expectations (subjectively), and beliefs about the existence of factors can facilitate or inhibit behavioral performance and perceived strength of these factors (perceived behavioral control). In their respective groups, behavioral beliefs produce favorable or unfavorable attitudes towards behavior; normative trust produces perceived social pressure or subjective norms, and control of beliefs gives rise to perceived behavioral control.

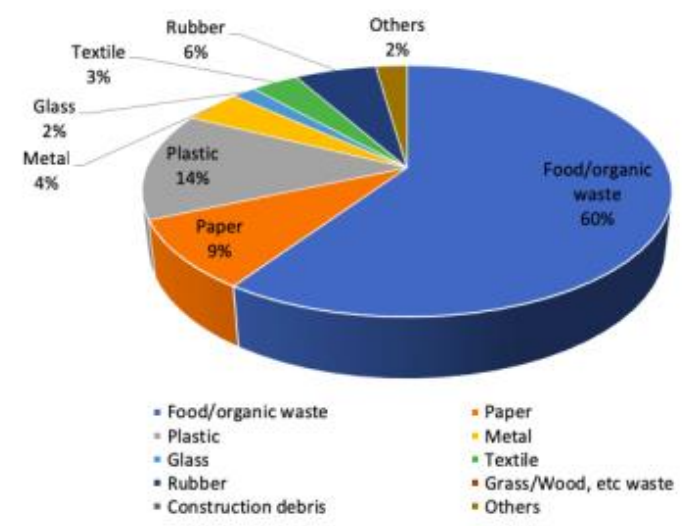

Fig 2. MSW composition (\%) in Indonesia [7] 
In combination, attitudes toward behavior, subjective norms, and perceptions of behavioral control lead to the formation of behavioral intentions. As a general rule, the more favorable the attitudes and subjective norms, and the greater the perceived control, the stronger the intention of the person to carry out the behavior. Finally, given the level of actual control that is adequate for behavior, people are expected to carry out their intentions when they have the opportunity. Also, Banga [20] investigates that participation in solid waste separation activities depends on the level of awareness of recycling activities in the area, household income, educational level and gender (Demographic). Therefore, demographic factors are added to the TPB model for further analysis, as shown in Fig. 3.

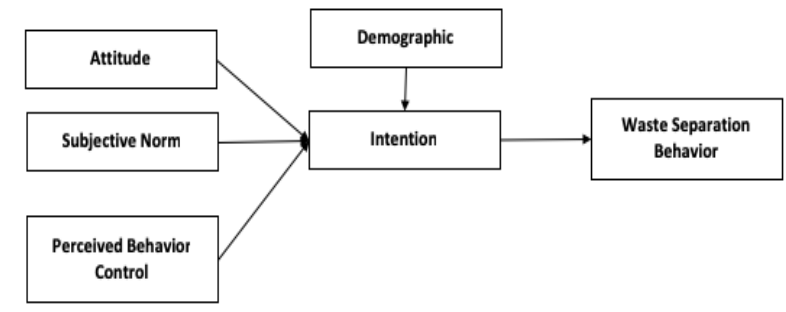

Fig 3. Adopted Theory of Planned Behavior Model

\subsection{Statistical questionnaire survey analysis}

The preparation of the questionnaire in this study was based on literature studies and semi-structured interviews that had been done previously. The design of the questionnaire is divided into 2 parts, where part 1 consists of 6 parts of the question. Questionnaire questions in section 1 contain basic information from respondents. The questions in part 1 are gender, age, education, occupation, status, income per month.

While the questions for part 2 are based on the conceptual model and predetermined indicators. Questions are made using a Likert scale with 5 choices of answers (strongly disagree, disagree, doubt, agree, and strongly agree). The question in section 2 is intended to describe the behavior of the community in the activity of sorting household waste.

To calculate significant factors in influencing people's behavior in sorting household waste based on the Theory of Planned Behavior by using the help of partial least square (PLS). Partial least square uses two models in the Structural equation modeling (SEM), namely inner and outer models [21].

In the outer model, testing is done to determine the level of reliability and validity of the model to be used. The reliability tested is the Composite Reliability value which must be greater than or equal to 0.6 and the Reliability Indicator value must be greater than 0.4 . In addition to the reliability of the validation test also carried out by looking at the value of the Discriminant Validity and Convergent Validity which must be greater than 0.5 .

\section{Result And Analysis}

\subsection{Questionnaire Survey}

This research was carried out within the area of DKI Jakarta and Depok. The choice of the location of DKI Jakarta as a place for sampling is because the area is small but has a large population and DKI Jakarta is a center of government as well as an economic center so that it is considered to have a large potential waste problem. And the area is quite representative of the demographics of the Indonesian people because many people outside the area settled there. While the Depok region was chosen because it is one of the supporting areas of DKI Jakarta.

Table 1. Reliability Measurement

\begin{tabular}{|c|c|c|c|c|}
\hline $\begin{array}{c}\text { Variable } \\
\text { Laten }\end{array}$ & Indicator & $\begin{array}{c}\text { Reliability } \\
\text { Indicator } \\
(>\mathbf{0 , 5 0 )}\end{array}$ & $\begin{array}{c}\text { Composite } \\
\text { Reliability } \\
(>0,60)\end{array}$ & $\begin{array}{c}\text { AVE } \\
(>\mathbf{0 , 5 0})\end{array}$ \\
\hline $\begin{array}{l}\text { LV 1: } \\
\text { Demogr } \\
\text { aphic }\end{array}$ & $\begin{array}{l}\text { D1 } \\
\text { D2 } \\
\text { D3 } \\
\text { D4 }\end{array}$ & $\begin{array}{l}0,68 \\
0,74 \\
0,75 \\
0,69\end{array}$ & 0,806 & 0,51 \\
\hline $\begin{array}{l}\text { LV 2: } \\
\text { Attitude }\end{array}$ & $\begin{array}{l}\text { A1 } \\
\text { A2 } \\
\text { A4 } \\
\text { A5 }\end{array}$ & $\begin{array}{c}0,81 \\
0,7 \\
0,76 \\
0,75\end{array}$ & 0,84 & 0,568 \\
\hline $\begin{array}{l}\text { LV 3: } \\
\text { Subjecti } \\
\text { ve } \\
\text { Norm }\end{array}$ & $\begin{array}{l}\text { S1 } \\
\text { S2 } \\
\text { S3 } \\
\text { S4 } \\
\text { S5 }\end{array}$ & $\begin{array}{c}0,7 \\
0,74 \\
0,69 \\
0,78 \\
0,67\end{array}$ & 0,838 & 0,51 \\
\hline $\begin{array}{l}\text { LV 4: } \\
\text { Perceive } \\
\text { d } \\
\text { Behavio } \\
\text { r } \\
\text { Control }\end{array}$ & P3 & 1 & 1 & 1 \\
\hline $\begin{array}{l}\text { LV 5: } \\
\text { Intentio } \\
n\end{array}$ & $\begin{array}{l}\text { I1 } \\
\text { I2 } \\
\text { I3 }\end{array}$ & $\begin{array}{c}0,85 \\
0,9 \\
0,83\end{array}$ & 0,895 & 0,74 \\
\hline $\begin{array}{l}\text { LV 6: } \\
\text { Waste } \\
\text { Separati } \\
\text { on } \\
\text { Behavio } \\
\text { r }\end{array}$ & K1 & 0,75 & 0,84 & 0,638 \\
\hline
\end{tabular}

The distribution of the questionnaire was carried out with 301 correspondents and spread it online. The distribution 
of questionnaires online is done with the help of available social media such as WhatsApp and Twitter. The online questionnaire is distributed from February 15, 2019 to April 5, 2019.

\subsection{Perception Analysis}

Based on the analysis of the results of the questionnaire found it was found that attitude became a significant factor, this is in accordance with the research that has been done before [22]. Ajzen [23] suggests that attitudes toward behavior are determined by beliefs about the consequences of a behavior. Beliefs are related to individual subjective judgments of the surrounding world, individual understanding of themselves and their environment, done by connecting between certain behaviors with various benefits or losses that might be obtained if individuals do or do not do it. This belief can strengthen the attitude towards the behavior if based on an evaluation conducted by an individual, data can be obtained that the behavior can provide benefits for them.

Several previous studies support the findings of this research, that subjective norm is not a significant variable. The subjective norm seems to be the factor that contributes less to any explanation of the intention [24, 25].

\section{Conclusion}

This study is a development of the Theory of Planned Behavior model to identify key factors that encourage the sorting of household waste from its source. Based on the results of the processing and analysis of data shows that the attitude variable has a significant influence on the intention to sort household waste and has a significant influence on the behavior of sorting household waste. Based on the research also found that intention has a significant influence on the behavior of sorting household waste.

Suggestions for further research are the location of data collection can be expanded into one island or one country so that it can provide results that are sufficiently representative of the size of a country. In addition, research can use other latent variables that have a strong enough influence on behavior such as adding regulatory variables and supporting infrastructure.

\section{Acknowledgement}

This work has been supported partially by PITTA 2019 Grant funded by DRPM University of Indonesia under contract No: NKB-0731/UN2.R3.1/HKP.05.00/2019.

\section{References}

1. D. Grazhdani, Assessing the Variables Affecting On the Rate of Solid Waste Generation and Recycling: an Empirical Analysis in Prespa Park, Waste Management 48, 3-13 (2016)
2. E. Drost, Validity and Reliability in Social Science Research, International Perspective on Higher Education Research 38,105-124 (2011)

3. E. Rudnik, Compostable Polymer Materials, Amsterdam: Elsevier Science (2008)

4. A. Heidari, M. Kolahi, N. Behravesh, M. Ghorbanyon, F. Ehsanmansh, N. Hashemolhosini, F. Zanganeh, Youth and Sustainable Waste Management: a SEM Approach and Extended Theory of Planned Behavior, Journal of Material Cycles and Waste Management 20(4), 2041-2053 (2018)

5. C. Mbande, Appropriate Approach in Measuring Waste Generation, Composition and Density in Developing Areas, Journal of the South African Institution of Civil Engineering 45, 2-10 (2003)

6. T. Karak, R.M. Bhagat, P. Bhattacharyya, Municipal Solid Waste Generation, Composition, and Management: The World Scenario, Critical Reviews in Environmental Science and Technology 42(15), 1509-1630 (2012)

7. A. Jain, Waste Management in Asean Countries. Thailand: United Nation Environment Programme (2017)

8. Badan Pusat Statistik. Indonesia: Badan Pusat Statistik (2014)

9. W. S. Purba, Indonesian Environmental Statistics, Indonesia: Badan Pusat Statistik (2017)

10. Law of the Republic of Indonesia Number 18 Year 2008

11. Government Regulation of the Republic of Indonesia Number 81 Year 2012

12. Regulation of the Minister of Environment of the Republic of Indonesia Number 13 of 2012

13. A.S. Permana, Sustainable Solid Waste Management Practices and Perceived Cleanliness in a Lowincome City, Habit International 49, $197-$ 205 (2015)

14. Y. Hui, W. Li'Ao, S. Fenwei, H. Gang, Urban Solid Waste Management in Chongqing: Challenges and Opportunities, Waste Management 26(9), 10521062 (2006)

15. L. Yang, Z.-S. Li, and H.-Z. Fu, Model of Municipal Solid Waste Source Separation Activity: A Case Study of Beijing, Journal of the Air \& Waste Management Association 61(2), 157-163 (2011)

16. W. Azlina, W.A.K. Ghani, I.F. Rusli, D.R.A. Biak, A. Idris, An Application of the Theory oPlanned Behaviour to Study The Influencing Factors of Participation in Source Separation of Food Waste, Waste Management 33(5), 1276-1281 (2013)

17. I. Ajzen, The Theory of Planned Behavior, Organizational Behavior and Human Decision Processes 50(2), 179-211 (1991)

18. M. Tonglet, P.S. Phillips, A.D. Read, Using the Theory of Planned Behaviour to investigate the determinants of recycling behaviour: a case study 
from Brixworth, UK, Resources, Conservation and Recycling 41(3), 191-214 (2004)

19. K.S. Fielding, R. Mcdonald, W.R. Louis, Theory of Planned Behaviour, Identity and Intentions to Engage in Environmental Activism, Journal of Environmental Psychology 28(4), 318-326 (2008)

20. M. Banga, Household Knowledge, Attitudes and Practices in Solid Waste Segregation and Recycling: The Case of Urban Kampala, Zambia Social Science Journal 2, 27-39 (2011)

21. A. Monecke, F. Leisch, Sempls: Structural Equation Modelling Using Partial Least Squares. Journal of Statistical Software 48, 1-32 (2012)

22. M. Tonglet, P.S. Phillips, A.D. Read, Using the Theory of Planned Behaviour to Investigate the
Determinants of Recycling Behaviour: a Case Study from Brixworth, UK. Resources, Conservation and Recycling 41, 191-214 (2004)

23. I. Ajzen, Attitudes, Personality and Behavior, (2nd edition), Berkshire, UK: Open University PressMcGraw Hill Education (2005)

24. C. Knussen, F. Yule, J. MacKenzie, M. Wells, An Analysis of Intentions to Recycle Household Waste: the Roles of Past Behaviour, Perceived Habit, and Perceived Lack of Facilities, Journal of Environmental Psychology 24, 237-246 (2004)

25. L. Mannetti, A. Pierro, S. Livi, Recycling: Planned and Self-Expressive Behaviour, Journal of Environmental Psychology 24, 227-236 (2004) 